\title{
Bayer MaterialScience Opens New Laboratory in Dubai
}

Bayer MaterialScience has inaugurated a new coatings, adhesives and specialties laboratory in Dubai. This application and development lab will offer local customized technical support to the industry across the Middle East and Africa. It is housed in the premises of DuBiotech, the major life science cluster in the region.

n addition to key application areas such as construction, automotive, industrial, plastic, wood and furniture coatings, the laboratory will also advance the development of polyurethane coatings for diverse high-performance applications. Recent examples are sealants for construction joints as well as airport tarmacs and solvent free coatings for pipe applications. The laboratory will also provide tailor-made solutions to manufacturers of adhesives and sealants for the transportation, construction, furniture, packaging and shoe industries.

"We must adjust our resources according to the market needs," said Daniel Meyer, Head of the Coatings, Adhesives, Specialties Business Unit and member of the Executive Committee of Bayer MaterialScience. "We are therefore making targeted investments in the individual regions in order to maintain or further expand our leading market position."

The laboratory will work in close cooperation with Bayer's global com-

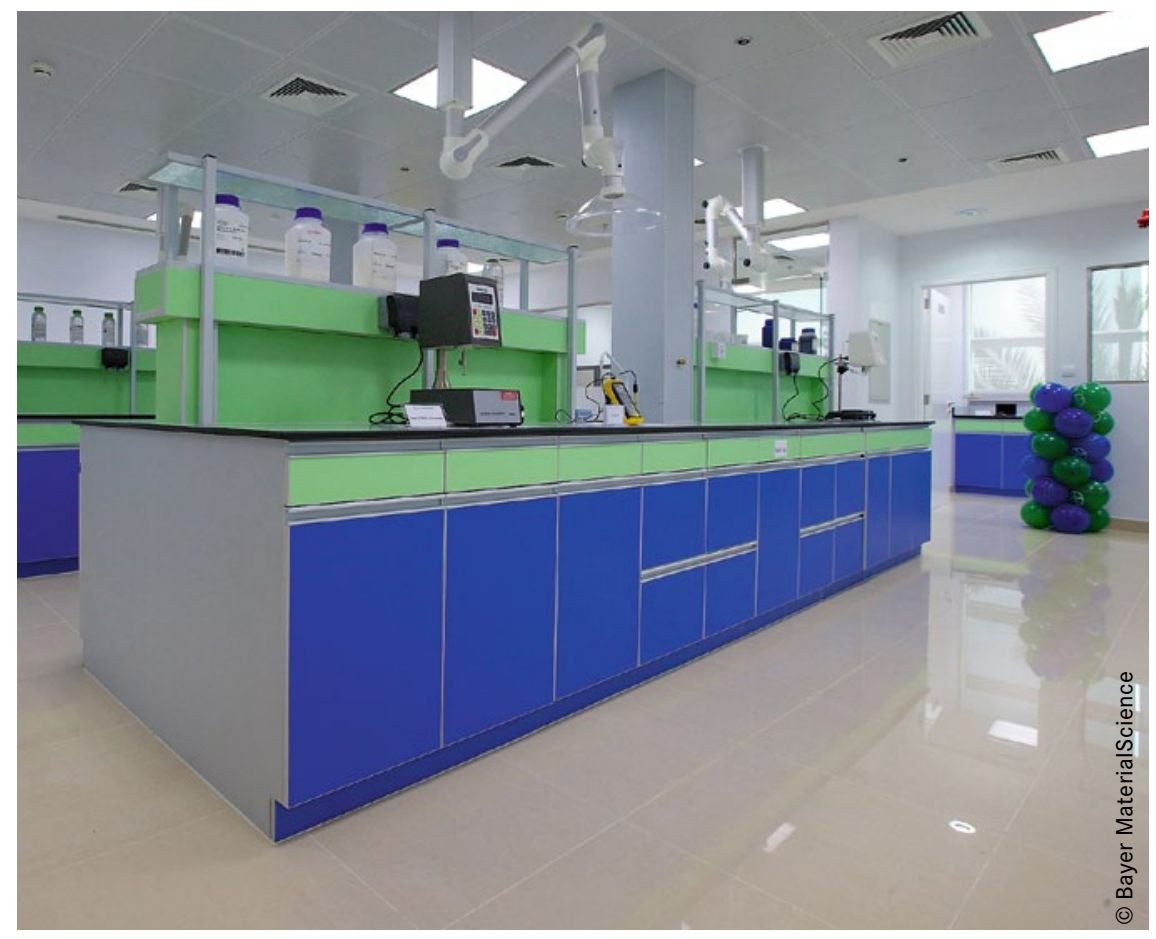

petence network, with its established laboratories and technical centres in India, China, Japan, Russia, Brazil, USA, Spain and Germany. The new facility is located in DuBiotech in Dubai and is equipped with advanced testing and application equipment. Like the science centre, the Bayer laboratory works in accordance with global standards and guidelines.

\section{Bossard Invests in BigHead}

The Bossard Group has acquired a stake in the British company BigHead, which is known in the field of high-performance fastening solutions. The special advantage of this acquisition is the global distribution partnership outside the UK.

$\mathrm{B}$ igHead has made a name for itself in particular in lightweight engineering and specifically in the field of composite materials. Premium car manufacturers such as Rolls Royce Motors, BMW, Aston Martin and Lamborghini use the company's fasteners, as do the renowned shipbuilders Sunseeker Yachts and the RNLI. BigHead's customers also include companies in the construction, petrochemical and wind power industries. The BigHead product range currently includes 400 standard designs, but alongside the fasteners well-known under the BigHead brand name, there are also customer-specific designs.

In 2013, BigHead generated sales of around CHF 4.0 million. Bossard sees great potential for growth in the British company's business, especially as it will benefit from the Bossard Group's global sales network. The Bossard Group recorded sales of CHF 609.7 million in 2013, with more than 1,800 employees at more than 60 sites worldwide. 